\title{
Analysis of benefits from being in a Alzheimer Internet support group for the caregivers of the people suffering from Alzheimer's disease
}

\author{
Bartosz Grobelny, Małgorzata Awdziejczyk, Wojciech Gorczyński, Marcin Janczyk, Marta \\ Leszczyńska, Katarzyna Meissner, Agnieszka Roszyk, Radosław Specjalski, Paulina Śniegula, \\ Jolanta Tomczak, Katarzyna Wiecheć
}

Clinical Psychology and Psychosomatic Medicine Academic Circle, Poznan University of Medical Sciences

\begin{abstract}
Both emotional and physical demands faced by Alzheimer's disease caregivers are very difficult to meet. Often, the amount of strength and calmness needed to fulfil the role of caregiver is beyond the person's adaptability. The aim of this article is the data analysis of the Alzheimer's disease caregivers online support groups and problems the caregivers face on the daily basis. Authors compared discussions and solutions available in polish language with methods used in other countries. The study was conducted in late April and May of 2013 by analyzing the user posts found on Polish webistes that associates the caregivers of people suffering form Alzheimer's disease. Authors assumed that there is a difference between citizens of different countries in the access to useful information that may help in solving daily problems. Confirmation of this hypothesis may indicate the need for modifications by creating a professional platform that associates Alzheimer's disease caregivers. Authors also analyzed remedies caregivers use and emotional functioning. By presenting recurring problems regarding diagnosis, burnout and coping with daily stress. They try to answer important question: what must be done to meet the needs of caregivers presented via the message boards. They are trying to prove that access to professional knowledge and presence in the environment that brings together caregivers can significantly improve level of performance and satisfaction. Even if the aid is granted only through an online platform of information sharing, the support effects are clearly visible.
\end{abstract}

Key words: Alzheimer's disease, caregivers, discussion boards, support groups.

\section{Introduction}

The aim of the paper is the presentation and review of the Alzheimer's disease caregivers problems. The requirements facing the caregivers of the people suffering from Alzheimer's disease are very challenging and cost a lot of effort. Senile dementia is an illness that hurts both the patient and his/her family. Taking care of a person with an Alzheimer disease requires a great deal of sacrifice - the person needs to be washed, dress up, fed etc. It has its social implications as well - one has to give up the social life he/she had and change family relations. As the result the caregiver often becomes alienated and left alone. The nurturance also leads to greater amounts of stress - the caregiver might worry what happens if he/she gets sick. Often the family members worry also about their kids being around a person suffering from Alzheimer's disease. The sick person requires all-day-long care, forcing the caregiver to sacrifice their work for the wellbeing of the sick person. Often they do not have sufficient funds to guarantee a necessary comfortableness to the person with dementia. Additional protections around the house, rails to help one move around, medicine drugs - it all requires enormous financial investment. 
In Poland the frequency of Alzheimer's disease distribution increases by $1 \%$ among people between 60-65 years old, and even by $40 \%$ among people aged 85 . Currently around 400 thousand people are suffering from the dementia, among which 50-70\% deal with Alzheimer's disease [1]. The number of people suffering from dementia is steadily rising while the number of proper health centres stays the same. Only about $3 \%$ of patients with dementia live in educational care centres and only $6 \%$ of the caregivers are satisfied with those organisations [2]. 92\% of the patients stay at home, being taken care of by their family for whom it becomes a great burden, as already explained. If often happens that the caregivers are partners of the sick person, who also reach the age of 60 and are not really able to properly take care of their loved ones. As a result, dementia has two faces-both in the form of a sickness hurting the patient and negative effects and burdens hurting the caregivers [3].

All the mentioned facts and the problems outlined resulted in caregivers' communal decision to associate and create their own space, the most accessible one in the XXI century - on the Internet. It is precisely the Internet, namely all the forums, blogs, virtual support groups and online editorials, that became the place where caregivers try to help one another. Believing that only a person in a similar situation is able to understand their suffering, they try as much as they can to exchange knowledge, advice, experiences, share their emotions, challenges and search for contact with another human being. People are being shuffled around from one doctor to another until they find the forum where they can find the answers they were looking for- more or less satisfying. Net surfers ask about symptoms, how to understand them and how to behave around Alzheimer's patient. They seek general information and ask about individual cases. They post that they lack someone who could monitor the patient and help with the duties around the patient. They complain about losing their own life while searching for friends online. On top of that, aside of standard queries, sometimes they ask questions that are much more individual in nature, which touch on problems, occurring less often.

Due to high ratio of people suffering from dementia to professional caregivers and because of the lack of sufficient financial support from the government it is virtually impossible to solve every problem that the caregivers might face. However, it is crucial to at least deal with the basic challenges, such as professional diagnosis and guidelines, whilst in terms of other challenges (psychological, physical, financial) none of the caregivers were left alone. It is worth underlining that professional advice and kind words are extremely valuable and helpful-whether they are spoken out loud or written on the Internet forum. The issue raised in this paper is about facing the challenges and needs described by the Internet users.

\section{The picture of the environment of the caregivers of the people suffering from Alzheimer's disease}

XXth century has brought dynamic development of the idea of mutual-aid and creation of numerous movements and organisations dealing with this issue, hence various systems of self-support for people with similar problems, including health problems. Those ideas sprung from the imperfect and insufficient health-care systems, not dealing with needs of the sick people, and lack of social support in the traditionally practiced medicine [4].

Among the people taking care of the Alzheimer's patients exist many movements or forms of self-help. There are support groups at the hospital wards, rest homes, hospices, institutions of social help etc. On the Internet one can find multiple sites for the caregivers of the dementia patients, on which we often find fragmentary knowledge, hardly useful tips etc. That is yet another reason explaining why caregivers associate themselves using the Internet forums.

Within the Internet the caregivers most commonly ask questions about a very specific symptoms of individual patients. Often it is possible to find the whole history and progress of illness for particular people. Sharing all the information about the sickness might therefore serve as a form of education. Caregivers experience complete lack of or insufficient amount of real help through sharing information, organising various forms of rehabilitation, cooperation with families, professionals, institutions, and sometimes financial help. The Internet forums also feature pieces about physical and psychological exhaustion of the caregivers themselves.

Taking care of the family member with dementia is very burdensome; the caregivers must show great patience and understanding. They are usually solitary in their struggle, forced to the continuous, all-day-long nurture over the sick person. As a result they are practically isolated from any social life. The behaviour of the sick person is highly unpredictable; hence the caregivers must continually face new challenges and situ- 
ations. To deal with them he/she needs professional support and knowledge. Just like Mrs Jolanta explains: "the sick are lost in their surroundings, they act abnormally and irrationally, weird even, i.a. they hide different objects in the strangest places, and then they try to find it [...] The sick keep repeating something stubbornly, they are hyperactive, even aggressive sometimes or they decline carrying out the most basic activities, like washing up [...] Such behaviour shocks and surprises, for the people around they seem funny or are suspected of acting out of spite, they cause dejection for the caregivers, and nervousness - says Mrs Węsierska [...] Often, though inaccurately, the Alzheimer's disease is associated with psychological illness, while it is a neurological disturbance [...] What is needed are drugs, therapy and lots of patience" [5].

Such intensive and burdensome care must put destructive pressure on the family life, career and social relations of the caregiver, resulting in many offshoots of the drawn-out stress, like: insomnia, irritation, anger, shame, loss of feeling of self-worth, guilt, depression, and also aggressive (both active and passive) behaviour towards the sick. It also results in frequent occurrence of serious health conditions among the caregivers associated with heart problems, arterial hypertension, joints' degeneration, diabetes, or gastric disturbances. "It has been proved that taking care of the dementia patient is more burdensome and stress causing than taking care of the people with somatic illnesses" [6]. This burden becomes even greater in the mentioned situation of financial problems, lack of sufficient knowledge about the sickness and the rules of care, inability to cope with new and escalating health problems of the sick person.

The caregivers often find themselves misunderstood by the family members or other people, which might lead to isolation in action. Internet forums point out to numerous problems with which the caregivers of the Alzheimer's patients must face and how important for them is their mutual psychological support and how they need all the forms of real help. "Hence the inseparable element of dealing with the dementia patient must be a psychological and material support of his/ her caregiver, and ensuring the support of other people and regular rest [...] Support groups, which should be attended by both the caregivers and the sick, allow for emotional abreaction from the care and exchange of experiences, and also supply practical advices about the progress of the sickness [...] The caregiver can also use the legal advice, information services about the nursing methods, and rehabilitation equipment" [6].

\section{Analysis of Internet forums content - caregivers' problems}

The issue is extremely problematic from the very beginning. First of all, people see the change in the behaviour of a close person but are unable to diagnose it properly. They are not certain whether it is the right moment to contact the specialist. This issue is especially problematic when dealing with the older people. Many assume that old age has its laws and hence cannot distinguish between dementia and the negative influence of aging.

Another problem presents itself when the caregiver realizes that the sickness has probably started and tries to consult with the doctor. The wards often treat visits to the hospital with great suspicion and it often happens that they decline to consult the doctor. Even if convinced otherwise, they tend to assert that everything is just all right.

How to take care of such a person? Many caregivers of the dementia or Alzheimer's patients frequently ask questions on the Internet forums dealing with this problem. They rather bring up issues of a specific behaviour. Hospitals often have their own, specialised ways of dealing with such situations, yet no one shares this information or gives advice to the caregivers how to deal with them in the home environment. Aside of issues like feeding the sick that does not want to eat, or changing the diapers, what caregiver often ask about are: controlling the finances of the sick, giving medicine, general advice behaviour, where to look for support, information and advice, the lack of reliable information about the sickness and possibility of support.

Demanding and long-lasting care over the sick is extremely engaging and exhausting. It creates a myriad of problems that are emotional and even psychological in nature, e.g. stress, inability to cope with new situations, inability to keep one's distance, helplessness and problems with physical health.

The caregivers often deal with numerous angsts and moral dilemmas. Many Internet posts show great doubt towards the nursing homes. Aside of financial issues, people are afraid of bad treatment in such facilities. Many also face the feeling of guilt believing that putting a relative in a nursing home is simply getting rid of him, often not realising that care at such facilities usually is much more stress less and safe than at home.

The frequent consequence resulting from taking care of the sick is resigning one's work. Significant number of people writing on the Internet forums informs that they needed to give up their careers for 
the sake of taking care of the older person. Often it is a result of indifference of the rest of the family, which forces one person to take the entire burden. The caregivers then sacrifice themselves entirely in the feeling of duty. As the consequence of spending the whole day with the ward is losing friends, which in turn results in feelings of loneliness and depression. Losing the social skills by the people who take care of the sick person for so many years change their functioning style so much that they are unable to function in normal conditions.

The reaction of the environment turns out to be no less problematic than that. It is often very negative in nature. People often do not know what the disease leads to and how it operates which results in inadequate judgments of the Alzheimer's patients, and other dementia-related diseases, and strong criticism of the family. Some also do not appreciate the burden that the caregivers need to deal with- they accuse the family of not paying a proper attention, neglecting the sick, of deliberately mistreating the patient.

Often a long-term, all-day-long care of the sick person leaves a mark on a caregiver's psychic. Such people often complain about various psychological disorders. The tragedy of the caregivers usually does not even stop when they cease to take care of the sick. It continues even when the patient is sent to the nursing home (Table 1).

\section{Possible solution of the problem}

Based on the analysis of the situation in the Anglo-Saxon countries - The Great Britain - one can see that there are numerous Internet sites dedicated to the Alzheimer's disease which also include expanded sections about support for the caregivers. In this chapter we will cover ways of providing Internet support functioning in other countries. We will also evaluate the need for providing the Polish equivalent of those sites, offering support to the people engaged in taking care of the sick.

The Internet provides extended guidebooks informing how to treat the sick person, how to take care of one's own physical and psychological health, and also how to plan financial expenditure. Those guidebooks are available both in the form of plain text and multimedia $[12,13,14]$.

At the Alzheimer's Association website one can find questionnaires enabling the initial diagnosis of the emotional state of the caregiver and a telephone support line for the caregivers. The people handling the support line offer wide-range of support from offering the basic information regarding i.a. cognitive deficits occurring at the initial stage of Alzheimer and explain how to deal with crisis situations [12].

The foreign websites also enable access to the database of specialist agencies and institutions that deal both with personal problems of the caregivers and that of the patient that exceed the abilities of the caregiver, but requiring a professional health service $[15,16]$. There are also Internet applications available, among which are [12]:

- Those that enable planning the future events for the caregiver and the Alzheimer patient - the programme aims at inspiring awareness in terms of future needs such as: adjusting the house to patient's needs or car driving

- Event-planner/Calendar

- Virtual library - containing the collection of scientific research and articles dealing with Alzheimer disease.

American group called "Alzheimer's Association" on its website offers access to a wide range of multimedia resources, including educational videos. It is possible to find statements there of distinguished academics on the important role of early diagnosis in Alzheimer patients, current research [12], or effectiveness of various medicines [12]. On top of that, people seeking support may access videos with useful advice on an appropriate diet, rich in antioxidants, or the most advantageous physical exercise for the sick patient [12].

The caregivers of the Alzheimer patients, by signing up on the website [12], give their consent to receiving a weekly newsletter created by the association's members. It is an email, which contains the most recent scientific and political news, so information about newest scientific discoveries and government activity for patients with dementia. Additionally, the e-newsletter contains information about a newly created support groups, trainings for the caregivers or short workshops such as "basic communication skills with Alzheimer patient".

Majority of the foreign websites dedicated to Alzheimer's disease allow virtual contact with specialists in this disease. And so, for instance, the American foundation for Alzheimer patients offers a service called: "Ask the expert" [18] on its website. The specialists offer professional advice on-line and answer questions of the people engaged in taking care of the sick, treating each case with an individual approach. The website also features the ranking of the most often discussed issues and professional advice of very qualified people. Visiting the website "Alzheimer's project" [19] 
Table 1. Problems and caregiver messages. Source: Own

\begin{tabular}{|c|c|}
\hline Negative influence of aging & $\begin{array}{l}\text { "After the death of my grandfather, grandmother got her first stroke, yet she recovered with only slight brain } \\
\text { damage and we did not detect any changes- trivially we missed the beginning of a sickness" [7]. }\end{array}$ \\
\hline Consulting the doctor & $\begin{array}{l}\text { "Father does not even want to hear about seeing the doctor [...] after seeing the neurologist the doctor wanted } \\
\text { to keep him for a 3-day observation and do a X-Ray computed tomography with contrast agents but he signed } \\
\text { his release for his own responsibility and the neurologist could not do anything about it. Anyway, it does not } \\
\text { really matter because once father visits a doctor he starts lying and distorting the facts, claiming that everything } \\
\text { is alright, that only his knee hurts" [8]. }\end{array}$ \\
\hline Controlling the finances of the sick & $\begin{array}{l}\text { "We are afraid of doling out money, or that someone will skew the grandmother when they see her problems } \\
\text { when dealing with cash. Would it be a good move to pay the money into a bank account for safety?" [7] }\end{array}$ \\
\hline Giving medicine to the sick person & $\begin{array}{l}\text { "I took my mother's medicine and hid it well, she won't be pilfering it anymore (...) only now she keeps arguing } \\
\text { about those drugs" [9] }\end{array}$ \\
\hline General advice behaviour & "I am looking for any advice regarding how to hush her. Can our behaviour have any tangible impact on her?!" [9] \\
\hline $\begin{array}{l}\text { Lacko of information where to look } \\
\text { for a support }\end{array}$ & $\begin{array}{l}\text { "Many posts on the Internet forums are titled "lack of professional help". One of the women wrote: "we travel to } \\
\text { the doctor with the mother in law but we lack support to know how to deal with such a person even at home, so } \\
\text { that there would not be any life-threatening situations" [10] }\end{array}$ \\
\hline $\begin{array}{l}\text { The lack of reliable information } \\
\text { about the sickness and possibility } \\
\text { of support }\end{array}$ & $\begin{array}{l}\text { "Maybe I am expecting too much but so far none of the doctors could tell me anything about the illness that } \\
\text { I did not already know myself" [9] }\end{array}$ \\
\hline $\begin{array}{l}\text { Psychological problems such as } \\
\text { stress }\end{array}$ & $\begin{array}{l}\text { "I live in constant stress. Anxiety. I constantly feel guilty. I cannot deal with it anymore. I am heartbroken...I suspect } \\
\text { that stress is what caused my two previous miscarriages"[9] }\end{array}$ \\
\hline $\begin{array}{l}\text { Inability to cope with new } \\
\text { situations }\end{array}$ & $\begin{array}{l}\text { "We were so close together once and I do not deny that I am dealing with it terribly...I see that I now exist only } \\
\text { in his memories" [9] }\end{array}$ \\
\hline Inability to keep one's distance & $\begin{array}{l}\text { "I see that mother cannot cope with it. Father's every action and behaviour discomposes her, she cannot distance } \\
\text { herself." [9] }\end{array}$ \\
\hline Helplesness & $\begin{array}{l}\text { "The grandmother does not listen to anyone. Even the grandfather has lost any influence over her. We feel } \\
\text { helpless" [7] }\end{array}$ \\
\hline Problems with physical health & $\begin{array}{l}\text { "We are psychologically exhausted, but we are starting to lose our physical health as well. We need to carry the } \\
\text { grandfather to the toilet" [9] }\end{array}$ \\
\hline Fear of wrong diagnosis & $\begin{array}{l}\text { "I am terrified with the fact that doctors state their diagnosis so easily because it makes it so much harder for us } \\
\text { to take care of him" [9] }\end{array}$ \\
\hline Losing friends & $\begin{array}{l}\text { "Lack of contact with other people sometimes drives me crazy"; "I could forget about having friends, only } \\
\text { a handful remained. My love will not last, but I am not surprised." [7] }\end{array}$ \\
\hline Losing social skills & $\begin{array}{l}\text { "I am terrified that I can no longer live normally, and now it is a pure prison for I even do not leave the house } \\
{[\text { [... I have no more patience for the healthy, living people, I avoid them as much as I can." [11] }}\end{array}$ \\
\hline Family neglection & $\begin{array}{l}\text { "Usually about twice a week the neighbours (suddenly eager to bring help) call the police because we are } \\
\text { "murdering the old lady". We heard: "God has punished you!", "You do not show enough understanding!", "There is a mad person in the house!", "It is sickness! What will you do when you become sick?!", "It is your } \\
\text { duty!", "You should be doing what she wants, you owe her that!" [10] }\end{array}$ \\
\hline $\begin{array}{l}\text { Long-term, all-day-long care of the } \\
\text { sick person leaves a mark on } \\
\text { a caregiver's psychic }\end{array}$ & $\begin{array}{l}\text { "Now A. is at the nursing home, we did not deal with it. I thought that everything will change now, but in the } \\
\text { meantime...everything became so irrelevant, I became indifferent to everything. I really cannot pull it together." [7] } \\
\text { "Mother's son came back to work. And what about me? I stayed all alone in the empty house. Then the all-- } \\
\text { encompassing silence made me realise that the challenge has been finally completed. At the finish was only } \\
\text { a deep wound in the heart, the burden of painful experiences which you cannot forget...and all-encompassing } \\
\text { abyss" [11] }\end{array}$ \\
\hline
\end{tabular}


we can find another possibility of having an on-line chat with one of the experts. The mentioned options make the flow of information between the people who need it - the caregivers - and those who offer it - specialists- very fast and fluent.

Volunteering is another interesting and useful option. In 1991 reverend John Fletcher, the Methodist pastor from Florida, introduced an innovative support programme which today is known as: "Alzheimer Project". Initially, the range of the services provided was very narrow and included mainly support for the caregivers within the parish. Currently, Alzheimer Projector operates in 12 counties in Florida, uniting people who want to help others. The idea of the organisation focuses on finding volunteers who can fill in for the caregiver and take care of the Alzheimer patient. People who want to perform such activity must register at the volunteer's base/headquarters and undertake a training preparing them for their future role. Then the volunteer is sent to the family that approached the organisation asking for help in order to spend few hours with the sick and substitute for the caregiver. Thanks to such services, the caregivers finally have time for themselves. The manager at the Alzheimer's Project underlines how important for the caregivers is the ability to take care of their own psychological and physical wellbeing. The volunteer visits a household once a week, taking care of the sick for 2-4 hours. The caregivers may spend this whole time on whatever pleasures he wishes, but for which he did not have time beforehand: from a long, afternoon to engaging in a long-forgotten hobby. The participants of the Alzheimer's Project call such visits the "rest time" [20].

Based on the foreign experience from Canada, USA or the UK we propose construction of the national web portal of the same character. When analysing the Polish interest resources dedicated to dementia diseases one realises the lack of sufficiently developed website offering the necessary information about the Alzheimer disease and advice for the caregivers. It does not mean that such information does not appear on the Internetfor instance there is an Internet guidebook that can be found on the alzheimer-poznan.pl website. [21] It is necessary to create an extended Internet platform dealing with Alzheimer's disease and offering support for the caregivers in Poland. Its core should be a fully featured guidebook containing information about:

- taking proper care of the Alzheimer patients

- taking proper care of one's own physical and psychological health when taking care of the Alzheimer patient
The information should be presented both in the form of text and multimedia. Among those materials there should be companions dealing with:

- taking care of physical and psychological health of both the caregiver and the patient (the proper diet, advantageous physical exercises, how to lower the stress level, how to deal with the feeling of loneliness)

- financial planning

- proper treatment of the sick person (time-planning based on patient's abilities, allowing for the greatest elasticity of his/her movements, organising patient's time and activities)

- problems and deficits that may occur (like memory loss).

The crucial issue is including the information about the medical institutions helping people with Alzheimer's disease. The caregivers could save a lot of time that would be otherwise wasted on trying to find the specialist help.

The website should also offer a possibility of contacting the psychologist. The support could be offered in either the form of e-mail (when dealing with minor issues) or Skype conversation (when dealing with serious situations and mental conditions of either the caregivers or the patient). The psychological support may also be offered indirectly through database of the therapeutic support groups.

The stress reduction and challenging the feeling of loneliness, besides the help of psychologist, may be offered by an Internet forum for the caregivers. Contacting other caregivers of the Alzheimer's patients would allow:

- exchange of precious information and advice

- acquiring support from other caregivers

- improvement of the psychological state through altruistic help offered to others

- discovering that caregivers are not solitary in their suffering.

How to utilise the idea of the pastor from the Methodist Church in Florida and implement it in Polish reality? Besides educational and informational services, the website should associate people who would like to help. The volunteers from different regions of the country through online registration would be added to the Internet database of the people offering their help and time for the families of the Alzheimer patients and patients themselves. The Internet search engines would allow the caregivers to find a volunteer in their closest neighbourhood. The project could also benefit greatly if the people from parish associations and student societies could also be engaged in the project. 


\section{Conclusions}

In the light of presented information we can see that taking care of Alzheimer patients/people suffering from Alzheimer requires enormous physical and emotional sacrifice. The requirements for the caregiver change on daily basis. He/She must dramatically change one's social life, i.e. relinquish the social relations and adjust one's free time to the needs of the sick. The caregiver may apply a long-term strategy based on acquiring a sufficient knowledge that would help in a day-to-day nurture of the sick. Training programmes teaching families about the development of the Alzheimer's disease and practical strategies dealing with crisis situations would be of great help.

Adjustment to new situations, skills learned through experience and strong web of support from the family may in substantial way help the caregiver in their daily struggles and care of the loved ones. Support groups also constitute an important element in the functioning of the caregivers. They allow the members to take a rest from their duties and burdens, and to share their doubts, exchange experiences, acquire an advice and get emotional support and understanding. The webs of self-support may be especially helpful when the caregivers face extremely difficult decisions and have nobody to talk to. Diagnosing the Alzheimer's disease leaves people with myriad of questions, to which answers are neither easy nor desirable. Getting solid information is impossible or they are not sufficient enough in a current situation. It is not just the patient's health that is problematic, but so are the finances, security, legal issues and planning the future. The caregivers must also remember about their own health and well-being. A proper diet, physical exercises, and stress-relief activities are important part of it.

At the time of a rapid technological development of the Internet there is a need emerging to create a webbased platform that would serve as the web of support associating all the caregivers dealing with people suffering from Alzheimer's disease. Thanks to analysis and evaluation of the statements of the caregivers made on the Internet we see a great need for creating a homogenous Internet service that will allow to acquire a sufficient knowledge from the professionals. However, above all such portal should facilitate the creation of associations of caregivers and the sick. It should be a community shaped on the basis of solid knowledge that the members could trust without a doubt. It will supply a necessary level of support and help necessary when working with the sick. What is more, it should be a platform that the caregiverscould access to find the newest knowledge and discoveries about those illnesses, including their progress and ways of restraining their development. It should unite the volunteers and allow them access to information about the people seeking their help. In the future it should coordinate actions of the volunteers with people seeking help- so that is becomes a place where caregivers could declare the need for volunteer help in real world. Finally, it should supply information about local facilities and institutions for both the caregivers and the sick. We hope that in Poland, as we have seen in the proud examples in the West, we will also have a professional platform of support for the caregivers that would meet their needs and requirements.

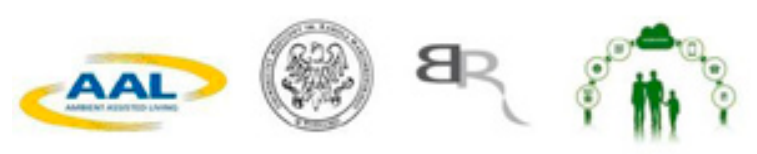

The article written as part of the research grant: UnderstAID - a platform that helps informal caregivers to understand and aid their demented relatives.

\section{References}

1. Kaczmarek M, Durda M, Skrzypczak M, Szwed A. Ocena jakości życia opiekunów osób z chorobą Alzheimera. Gerontologia Polska. 2010;18(2):86-94.

2. Durda M. Organizacja opieki nad osobami z demencją w Polsce na tle krajów rozwiniętych i rozwijających się. Gerontologia Polska. 2010;18(2):76-85.

3. Dang S, Badiye A, Kelkar G. The dementia caregiver - a primary care approach. South Medical Journal. 2008;101(12):1246-1251.

4. Turuk-Nowak T. Pomoc psychologiczna pacjentom onkologicznym. Zmagając się z chorobą nowotworową. W. Kubacka-Jasiecka D, Łosiak D (redaktorzy). Wydawnictwo Uniwersytetu Jagiellońskiego, Kraków. 1999; 237-41.

5. Kuczmarska A. Opiekują się swoimi bliskimi i wspierają siebie nawzajem. Puls Wejherowa. http://pulswejherowa. pl/start/531-opiekuj-si-swoimi-bliskimi-i-wspieraj-siebie -nawzajem, data access: 10.03.2013.

6. Polish Psychological Association. Psychotherapy and Alzheimer's Disease Department. Standard procedures: http://www.alzh.pl/standardy_2_14.html, data access: 10.03.2013.

7. Internet Forum of: Małopolska Fundacji Pomocy Ludziom Dotkniętym Chorobą Alzheimera. http://forum.alzheimer -krakow.pl/viewforum. php?f=4\&sid=3e3b310f1293f 128 f82cb9ac6cbb8358, data access: 10.03.2013.

8. Neurological Internet Forum: Portal Wiedzy O Neurologii. http://www.forumneurologiczne.pl/forum/vt,0,407, 24692,160, demencja-starczaalzheimer-bezradnosc-rodziny, data access: 10.03.2013. 
9. Alzheimer - Caregivers' Internet Forum: http://www. alzheimer-opiekuni.pl/forum/index.php, data access: 10.03.2013.

10. Commed Medical Forum: http://commed.pl/alzheimervt64796.html, data access: 10.03.2013.

11. Psychological Forum: Nervousness, Depression, Psychology. http://www.nerwica.com/alzheimer-t7305.html, data access: 10.03.2013.

12. Alzheimer's and Dementia Caregiver Center. http://www. alz.org/care, data access: 10.03.13.

13. AlzOnline Caregiver Support Online. http://alzonline. phhp.ufl.edu/, data access: 10.03.13.

14. Alzheimer Foundation for Caregiving in Canada. http:// www.alzfdn.ca/, data access: 10.03.13.

15. National Institute of Health. Health \& Aging Organizations Directory. http://www.nia.nih.gov/health/resources/search/alzheimers-disease, data access: 10.03.13.

16. MedlinePlus Alzheimer Caregivers. http://www.nlm.nih. gov/medlineplus/alzheimerscaregivers.html, data access: 10.03.13.

17. Wielkopolska Alzheimer Association: http://www.alzheimer-poznan.pl, data access: 10.03.13.
18. Assist Guide Information Services. http://www.agis. com/community/Ask-The-Experts/afa/default.aspx, data access: 10.03.13.

19. Alzheimer's Project. http://www.alzheimersproject.org, data access: 10.03.13.

20. Alzheimer's Foundation of America. http://www.alzfdn. org, data access: 10.03.13.

21. Baumann M, Buraczyk M, Knaś R, Przedpelska-Ober E, Rossa A. Poradnik dla opiekunów osób dotkniętych chorobą Alzheimera. Wielkopolskie Stowarzyszenie Alzheimerowskie. Poznań. 2008.

Correspondence address: Department of Clinical Psychology Poznan University of Medical Sciences 70 Bukowska Street 60-812 Poznan, Poland phone: +4861 8547274 email: psychologia@ump.edu.pl 